\title{
UM ESTUDO INICIAL SOBRE A REPRESENTAÇÃO DA IDENTIDADE DE CLASSE NO LIVRO DIDÁTICO PORTUGUÊS: LINGUAGENS
}

\author{
AN INITIAL STUDY ON CLASS IDENTITY \\ REPRESENTATION IN THE TEXBOOK \\ PORTUGUESE: LANGUAGES
}

\author{
Lilian Aparecida de Moura" \\ Valeska Gracioso Carlos**
}

Resumo: Este estudo trata-se de uma pesquisa qualitativa na área da Linguística Aplicada, que teve por objetivo a análise de um capítulo do livro didático Português: Linguagens, de Cereja e Magalhães, no que diz respeito às classes sociais e como elas são representadas e, desse modo, fazer uma intersecção com as variedades linguísticas. Como referencial teórico, contamos com Street (2007) no que concerne às práticas de letramento; Dambrós (2016) e Baladeli (2014) no que tange à identidade de classe social; Faraco (2015) e Possenti (2000) no que diz respeito à variação linguística nos livros didático, entre outros. Os resultados demonstram que o capítulo traz algumas atividades que se enquadram nas práticas de letramento ideológico. Todavia, trabalha apenas com a dicotomia pobre/rico, desconsiderando as demais classes sociais. Ademais, essa oposição é feita de maneira estereotipada. À vista disso, reafirmamos a relevância de trabalhos cujo objetivo é a análise de livros didático.

Palavras-Chave: Livro didático; Identidade de classe social; Variação linguística.

ABSTRACT: This study is a qualitative research in the Applied Linguistics area, which aimed to analyze a chapter of the textbook Portuguese: Languages by Cereja and Magalhães, regarding social classes and how they are represented, and thereby, intersect this representation with the linguistic varieties. As a theoretical framework, we have Street (2007) concerning literacy practices; Dambrós (2016) and Baladeli (2014) in refence to social class identity; Faraco (2015) and Possenti (2000) regarding the insertion of linguistic varieties in textbooks, among others. The results of this

\footnotetext{
" Mestranda do programa de Pós-graduação em Estudos da Linguagem da Universidade Estadual de Ponta Grossa (UEPG). Email: liapmo@hotmail.com.

"* Professora Doutora, na Universidade Estadual de Ponta Grossa (UEPG). Email: vgracioso@uol.com.br.
} 
research demonstrate that the chapter brings some activities that fit the ideological filtering practices. However, the chapter works only with a poor/rich dichotomy, disregarding other social classes. Moreover, this opposition is made in a stereotypical manner. Therefore, it reaffirms the relevance of works that aim to analyze textbooks. KEYwords: Textbook; Social class identity; Linguistic Variation.

\section{INTRODUÇÃo}

Considerando que o trabalho do professor de língua portuguesa de uma escola pública exige que este docente lecione em mais de uma turma, atue, por vezes, em mais de uma instituição escolar e em mais de um turno, temos como consequência o fato do livro didático acabar se tornando uma das principais ferramentas de trabalho. Sendo assim, dada a importância desse material nas aulas de língua portuguesa, refletir sobre como são representadas as identidades de raça, gênero e sexualidade e classe social é um tema sempre atual e necessário, uma vez que uma sala de aula nunca é homogênea, isto é, em uma mesma sala de aula convivem pessoas das mais variadas classes, gêneros, raças, credos, etc.

Tendo em vista o desafio do dia a dia do professor em trabalhar em uma sala de aula tão plural no quesito identidades, este trabalho ${ }^{1}$ pretende discutir a questão das classes sociais e como elas são representadas em um capítulo ${ }^{2}$ do livro didático Português: Linguagens ( $1^{\circ}$ do Ensino Médio), de Willian Roberto Cereja e Thereza Cochar Magalhães, da editora Saraiva, ano de 2016. Além disso, pretendemos fazer uma intersecção da representação das classes sociais apresentadas no livro com as variedades linguísticas atreladas a elas.

Para tanto, nossa fundamentação teórica se divide em duas partes principais: em um primeiro momento, abordamos questões gerais sobre práticas de letramento e identidade, para que possamos discutir mais a fundo as questões ligadas à identidade de classe social e a relevância da inserção adequada dessas classes no livro didático. Em um segundo momento, tratamos das políticas linguísticas no PNLD (Programa Nacional do Livro Didático), no que diz respeito às variedades linguísticas e à necessidade do trabalho com elas. Na sequência, trazemos a análise do capítulo do livro didático: Português: Linguagens, de Willian Roberto Cereja e Thereza Cochar Magalhães. Por fim, apresentamos as considerações finais e as referências bibliográfica.

\footnotetext{
${ }^{1}$ Este trabalho foi elaborado a partir de discussões teóricas feitas na disciplina Formação de professoras/es de Línguas, Identidade Profissional e Letramento Racial, ministrada pela Professora Doutora Aparecida de Jesus Ferreira, no Programa de Pós-graduação em Estudos da Linguagem da Universidade Estatual de Ponta Grossa.

${ }^{2}$ Optamos por analisar apenas um capítulo do referido livro por questões de organização do artigo.
} 


\section{DisCUSSÃo TEÓRICA}

\section{LETRAMENTO E IDENTIDADE: DELIMITANDO ALGUNS CONCEITOS}

Hoje em dia, há uma grande discussão acerca do termo letramento. Para quem estuda letramento é de conhecimento comum pensar nele como algo que vai além da simples decodificação linguística, ou seja, vai além da alfabetização. Entretanto, não é apenas isso. Letramento pode ocorrer em diferentes esferas e com diferentes saberes, isto é, letrar faz parte de uma dimensão maior de ensino/aprendizagem do que os saberes escolares propriamente ditos.

Além disso, segundo Street (2007), há diferentes práticas de letramentos: as práticas autônomas e as práticas ideológicas. De acordo com o autor, as práticas de letramento autônomas são baseadas em valores particulares, portanto são práticas fechadas em si. Já as práticas de letramento ideológicas são mais abrangentes, pois reconhecem "uma multiplicidade de letramentos; que o significado e os uso das práticas de letramento estão relacionados com contextos culturais específicos; e que estas práticas estão sempre associadas com relações de poder ideologia: não são simplesmente tecnologias neutras". Street (2007, p. 466).

Isto posto, cabe-nos agora pensar na questão do processo de construção de identidades, tanto do professor de língua portuguesa quanto dos alunos, pois concebemos que as práticas de letramento estão diretamente relacionadas com as questões de identidade no processo de ensino/aprendizagem.

Para começarmos a discussão sobre identidade de classe, precisamos primeiro delimitar o que entendemos por identidade e qual é o papel dela na construção do ser professor de língua portuguesa. Segundo Romero (2008, p.403), "a identidade entendida em sua natureza dinâmica, resultante de experiências e sentidos construídos social e historicamente pelo indivíduo em interações com os outros".

Logo, podemos afirmar que as identidades não são prontas e inflexíveis, mas sim estão em constante construção e reconstrução, visto que nós, professores, estamos em constante processo de interação com nossos alunos, desse modo construindo novos significados, novas experiências. Nesse sentido, pensar em identidades no contexto da aprendizagem é importante, pois, como assevera Mastrella-de-Andrade e Rodrigues (2014):

[t]ratar da identidade dos sujeitos da aprendizagem e também apropriado por permitir que lidemos com questões individuais e sociais de forma mais equilibrada, não dissociando o sujeito de seu contexto, não fazendo dicotomias entre fatores individuais/psicológicos e sociais, mas reconhecendo-os enquanto tais em sujeição à estrutura e, ao mesmo tempo, em agência e operação, num modelo de relação em constante formação e transformação. (MASTRELLA-DE-ANDRADE E RODRIGUES, 2014, p. 144). 
Portanto, professor e alunos estão em um permanente processo de construção e reconstrução de suas identidades, processo que é (re)construído mutuamente. "[A]s práticas identitárias se dão socialmente, nas relações sociais que estruturam o mover das pessoas”. (MASTRELLA-DE-ANDRADE; RODRIGUES, 2014, p. 146).

Nesta mesma direção, devemos pensar em como as identidades de gênero, raça, sexualidade e classe ${ }^{3}$ são trazidas pelo material didático, que muitas vezes é um dos únicos recursos pedagógicos disponíveis para o professor. "O LD é visto como sendo a espinha dorsal do currículo e, em alguns casos, de fato, torna-se o currículo". (AUERBACH 1995, p. 20 apud FERREIRA, 2014, p. 93). Sendo assim, passamos, no próximo tópico, à discussão sobre identidade de classe no livro didático.

\section{IDENTIDADE DE CLASSE SOCIAL NO LIVRO DIDÁTICO}

De acordo com Dambrós (2016, p. 24), poderíamos classificar como classe social um grupo de "pessoas que ocupam uma posição parecida, em condições de vidas parecidas, com práticas também parecidas" Logo, convivemos diariamente com pessoas advindas das mais diferentes classes sociais e, como professores, (e mais especificamente como professores de língua portuguesa) devemos ter em mente que nossa sala de aula não é homogênea, ao contrário, em uma mesma sala de aula podem coexistir pessoas de diferentes, classes, raças, credos, gêneros, ideologias, dentre outros.

Portanto, refletir sobre identidade de classe social é um tema sempre atual. Como explica Baladeli (2014),

[a] questão da identidade de classe se faz presente no material didático de forma a vincular um conjunto de valores próprios da classe dominante. Esse discurso quando diluído em textos verbais e não verbais, pode favorecer a internalização de certos valores e formas de pensar da cultura hegemônica como verdades. (BALADELI, 2014 p. 229).

Ou seja, a depender da forma como o material aborda determinado tema, e a depender também da forma como o professor encara a abordagem do livro, o jogo de poder simbólico pode pender para o lado da classe dominante, deixando assim à margem e sem voz as classes sociais mais baixas. Consequentemente, impactará negativamente na vida do aluno, pois quando certos assuntos não são trabalhados de maneira efetiva podem ajudar a cristalizar representações por vezes artificiais da realidade brasileira, desta maneira, possibilitando o surgimento de um sentimento de não identificação e, por conseguinte, não pertencimento por parte do aluno.

${ }^{3}$ Devemos lembrar que nesse trabalho focaremos apenas na identidade de classe social. 
De acordo com Dambrós (2016), admitir a divisão de classes é admitir, por consequência, a existência de um poder simbólico, que vem de cima para baixo, ou seja, os detentores desse poder são justamente as pessoas das mais altas camadas sociais, "e tal poder é que determina as 'igualdades' de oportunidades e isso vai depender das origens sociais dos estudantes, pois tendo em vista sua origem social, pode haver uma falsa noção de igualdade de oportunidades, a qual influenciará na formação desse aluno". (DAMBRÓs, 2016, p. 24).

Portanto, é necessário que o professor de língua portuguesa tenha um olhar crítico para o material didático, pois como argumenta Baladeli (2014)

[é] indispensável questionar sobre os sobre que aspectos dos grupos minoritários são apresentados e de que forma a visão hegemônica de cultura é problematizada ou, ainda, se há escamoteamento das vozes de grupos minoritários por conta de sua raça ou de sua classe social em face à não identificação com os valores que servem como referência discursiva, ou seja, em face à voz dos grupos dominantes. (BALADELI, 2014, p. 231).

As aulas de língua portuguesa, assim como o material didático, são excelentes fontes e espaço para a discussão e desmistificação das representações dessas classes sociais. Uma vez que há muitos mitos acerca dessa representação, como exemplifica Dambrós (2016), as pessoas pertencentes às classes sociais com um menor poder aquisitivo são muitas vezes vistas como preguiçosas, não escolarizadas, e, portanto, pouco inteligentes, entre outros aspectos negativos. Já o oposto é pensado sobre as pessoas pertencentes às classes sociais mais altas, que são geralmente retratadas como inteligentes, esforçadas, ocupando os cargos mais altos e com profissões de grande prestígio social, em outras palavras, apenas aspectos positivos.

Além disso, podemos incluir aqui a discussão sobre a variedade linguística desses grupos sociais, pois, como bem lembra Gnerre (1985, p.4), “[u]ma variedade lingüística 'vale’ o que 'valem' na sociedade os seus falantes", ou seja, as camadas sociais mais altas são aquelas que detêm a variedade que é vista como a de maior prestígio, que é seguida como modelo ao passo que as camadas sociais mais baixas são as que têm a variedade linguística estigmatizada, isto é, os que falam "errado", os que "assassinam a língua portuguesa".

Como pudemos observar, é de grande importância a maneira como são representadas as classes sociais no livro didático, tendo em vista que é por meio desta representação que é veiculado um conjunto de juízos de valor que podem ter impacto negativo na vida de nossos alunos, quando não trabalhados adequadamente. Além disso, as classes sociais têm uma relação direta com a variedade linguística do falante representado por elas. Portanto, passamos a discutir, no próximo tópico, as políticas linguísticas do Programa Nacional do Livro Didático (PNLD) no que diz respeito ao trabalho com as variedades linguísticas. 


\section{Políticas linguísticas no Programa Nacional do Livro Didático (PNLD)}

No que diz respeito à análise, compra e distribuição dos materiais didáticos usados nas escolas e colégios público no Brasil, contamos com o PNLD (Programa Nacional do Livro Didático), que foi criado pelo Ministério da Educação em 1985.

Ainda que um dos critérios para a escolha do livro didático de língua portuguesa pelo programa seja a incorporação de atividades que levem em conta as variedades linguísticas do português brasileiro, "[o] que temos visto, no entanto, ainda representa muito pouco frente à complexa questão que esse tema propõe" (CYRANKA 2015, p. 32), e como bem destaca Faraco (2015):

[o]s livros didáticos têm dado um tratamento muito superficial ao tema, no mais das vezes limitados à apresentação, algo folclorizada, da variação geográfica ou um tanto quanto estereotipada das falas rurais. Os livros didáticos deixam de fora a variação social que é, de fato, a verdadeira questão a ser enfrentada, já que ela serve de critério para os gestos de discriminação dos falantes e de violência simbólica. (FARACO, 2015, p. 20).

No que diz respeito ao trabalho com a variação linguística no contexto escolar, concordamos com o que propõe Possenti (2000), que afirma que a função da escola, e entendemos também como função do livro didático, não é ensinar uma variedade em detrimento das outras, mas sim "criar condições para que os alunos aprendam também as variedades que não conhecem, ou com as quais não têm familiaridade, aí incluída, claro, a que é peculiar de uma cultura mais “elaborada”'. (POSSENTI, 2000, p. 83, grifo do autor).

Finalizamos este tópico com uma afirmação de Soares (1986) que sintetiza muito bem a importância do trabalho com as classes sociais e com as variedades linguísticas representadas por elas nas aulas de língua portuguesa e no livro didático:

Um ensino de língua materna comprometido com a luta contra as desigualdades sociais e econômicas reconhece, no quadro dessas relações entre escola e a sociedade, o direito que têm as camadas populares de apropriar-se do dialeto de prestígio, e fixa-se como objetivo levar os alunos pertencentes a essas camadas a dominá-lo, não para que se adaptem às exigências de uma sociedade que divide e discrimina, mas para que adquiram um instrumento fundamental para a participação política e a luta contra as desigualdades sociais. Fazer um link para a próxima seção. (SOARES, 1986, p. 78 apud BAGNO, 2003, p. 178, grifos do autor).

Constatamos que para um ensino crítico de língua portuguesa é de suma importância a discussão de temas como classes sociais e variedades linguísticas, foco de nosso artigo. 
Concluída a discussão teórica, passamos à apresentação da metodologia de pesquisa no próximo tópico.

\section{Metodologia}

Este estudo trata-se de uma pesquisa qualitativa na área da Linguística Aplicada, visto que, como afirma Pennycook (2010, p. 10), a Linguística Aplicada relaciona-se com questões significativas para a educação crítica, como "gênero, classe, sexualidade, raça, etnia, cultura, identidade, política ideologia e discurso. E, fundamentalmente, torna-se uma dinâmica que abre novas questões que surgem a partir deste conjunto".

No que diz respeito aos procedimentos metodológicos, nos amparamos nos pressupostos da análise documental, pois, conforme coloca Dambrós (2016, p. 62), "para análise documental é relevante considerar como documento quaisquer materiais escritos, que podem ser leis, normas, decretos, arquivos e, entre outros, os livros escolares".

Para a análise selecionamos o capítulo sete: As variedades Linguísticas, que faz parte da primeira unidade do livro Português: Linguagem, de autoria de William Roberto Cereja e Thereza Cochar Magalhães, que se destina a alunos da primeira série do Ensino Médio. $\mathrm{O}$ livro em questão é da editora Saraiva, 2016, e já está em sua décima primeira reimpressão. Escolhemos este material por ser um dos livros de língua portuguesa mais citados pelos professores da área. Além disso, em uma pesquisa rápida no site do FNDE (Fundo de Nacional Desenvolvimento da Educação), concluímos que a Coleção Português Linguagens foi a mais distribuída nos últimos dois editais: 2015 e 2017.

\section{ANÁLISE DE DAdos}

Para uma melhor organização dos dados analisados, optamos por dividir esse tópico em duas partes. Em um primeiro momento, verificamos como ocorre a representação das classes sociais no livro didático Português: Linguagens. Em um segundo momento, observamos como são tratadas as variedades linguísticas representadas pelas classes sociais trazidas no livro.

\section{REPRESENTAÇÃO DAS CLASSES SOCIAIS}

Escolhemos para a análise o capítulo sete: As Variedades Linguísticas, que pertence à primeira unidade. A imagem de abertura dessa unidade trata-se de um trabalhador rural negro representado de costas, um trabalhador rural de uma região seca, possivelmente no sertão nordestino. $O$ que podemos perceber é que a imagem trata-se de uma representação

${ }^{4} \mathrm{http}: / /$ www.fnde.gov.br/programas/programas-do-livro/pnld/dados-estatisticos acesso em 13 de abril de 2019. 
cristalizada e estereotipada de uma classe social mais baixa. Com relação a essa imagem, é importante refletir sobre alguns porquês: Por que um homem ? Por que negro? Por que ele é representado de costas? Por que um trabalhador rural e não outro trabalhador?

Neste caso, a representação desse trabalhador é, na verdade, a reprodução de um estereótipo tanto de classe social quanto de raça, pois trata-se de uma imagem já cristalizada no senso comum: o pobre, geralmente negro, aquele que trabalha de sol a sol para garantir o básico para a sua família, além do mais, o pobre não é escolarizado, visto que está representado na base da pirâmide social e, portanto, não pode ocupar outros cargos a não ser o de trabalhador braçal.

Na sequência, os autores trazem um poema de Patativa do Assaré, poeta brasileiro bastante famoso, pois com pouca escolaridade, mas com extrema sensibilidade, é autor de uma série de poemas amplamente discutidos no meio escolar e acadêmico. Possivelmente a escolha do poeta deu-se para reforçar a imagem (estereotipada) de abertura do capítulo, isto é, pobre, trabalhador do sertão nordestino e pouco escolarizado, em uma tentativa de afirmar que, neste capítulo em questão, irão tratar também das camadas sociais mais baixas da população, pobres e não (ou pouco) escolarizados.

Após exercícios interpretativos sobre o poema, há um texto sobre as variedades linguísticas. Nesse texto, os autores reconhecem que há uma diferença de prestígio (não só linguístico), entre falantes da área urbana e os falantes da área rural. Contudo, essa diferenciação é feita de uma maneira simplista e generalizadora, pois o que é possível depreender é que os falantes da área rural falam todos da mesma maneira e todos "errados", como mostra o trecho a seguir:

As variedades do português que mais se aproximam da norma-padrão são prestigiadas socialmente. É o caso das variedades linguísticas urbanas, faladas nas grandes cidades por pessoas escolarizadas e de renda mais alta.

Outras variedades, faladas no meio rural ou por pessoas não alfabetizadas ou de baixa escolaridade, geralmente são menos prestigiadas e, por isso, frequentemente aqueles que as falam são vítimas de preconceito. (CEREJA; MAGALÃES, 2016, p. 78).

Em outras palavras, são colocadas em um mesmo grupo as pessoas da área rural, não escolarizadas ou com pouca escolarização, portanto, desprestigiadas socialmente, e o oposto desse primeiro grupo é composto por pessoas da área urbana, escolarizadas e das mais altas camadas sociais.

${ }^{5}$ Tendo em vista que a mulher tem um importante papel no trabalho rural nordestino. 
Há, ainda nessa unidade, uma tirinha que também representa novamente as classes mais baixas da população. É possível inferir isso pela representação estereotipada dos personagens. Trata-se de um grupo de jovens que comemoram o fato de que um deles agora é um astro do Rock e que, portanto, poderá pagar o dinheiro que deve a cada um deles. A tirinha contém várias gírias, possivelmente para representar a fala daquele grupo específico, mas também para reforçar negativamente a ideia de que as pessoas de classes sociais mais baixas têm uma variação linguística que não segue as "leis" ${ }^{\circ}$ da gramática normativa.

O que nos parece é que para os autores só existem os dois extremos: o primeiro rural, pouco escolarizado e de classe social baixa, e o segundo, urbano, escolarizado e de classe social alta, como se não houvesse uma faixa contínua ${ }^{7}$ entre esses dois extremos. Como aponta Bagno (2003, p. 141), "[u]ma coisa que devemos evitar sempre, ao tratar da realidade linguística do português brasileiro [e aqui acrescentamos as classes sociais] $]^{8}$, é a perigosa tentação de dividir essa realidade em dois blocos bem delimitados, distintos entre si".

Concluímos que o livro didático tem o poder de reforçar traços positivos, assim como traços negativos em relação à identidade de classe social, que é enorme neste país. Portanto, reduzir as classes sociais a dois extremos (rico/pobre) é desconsiderar a realidade brasileira e, de certo modo, continuar com a reprodução de juízos de valor já ultrapassados.

\section{VARIAÇÃO LINGUÍSTICA NO CAPÍTULO ANALISADO}

Já nas primeiras páginas, em uma espécie de carta ao estudante, os autores explicam que há diferentes tipos de linguagem e que é por meio dela que fazemos qualquer tipo de interação com nossos interlocutores. No entanto, as declarações realizadas no decorrer do capítulo contradizem a discussão inicial, pois segundo os autores,

[p]ara evitar que cada falante use a língua à sua maneira, em todo o mundo existem especialistas que registram, estudam e sistematizam o "bom" uso da língua, tomando como referência os escritos literários, o que dá origem à norma-padrão, uma espécie de lei que orienta o uso social da língua. Essa norma-padrão é a que está registrada nos dicionários e nos livros de gramática. (CEREJA; MAGALHÃES, 2016, p. 77).

Há alguns problemas na declaração acima, a começar pelo fato de os autores não delimitarem a modalidade de língua à qual estão se referindo, escrita ou falada, quando afirmam

\footnotetext{
${ }^{6}$ Usamos o termo lei, pois no livro as regras gramaticais são referidas como "uma espécie de lei que orienta o uso social da língua". (CEREJA; MAGALHÃES, 2016, p. 77).

${ }^{7}$ Bortoni-Ricardo faz uma discussão sobre esse contínuo, no que diz respeito à variação linguística, no livro Educação em língua materna: a sociolingüística na sala de aula (2004).

${ }^{8}$ Comentário das autoras.
} 
que "[p]ara evitar que cada falante use a língua à sua maneira". Como pesquisadores da área da linguagem sabemos que a língua falada não segue as mesmas regras da língua escrita, portanto, não há como padronizar a fala seguindo as regras da gramática normativa. Além disso, apesar de os autores comentarem, na sequência do texto, que ninguém fala a língua portuguesa de acordo como ela encontra-se descrita nos manuais de gramática normativa ${ }^{9}$, o que fica implícito na declaração anterior é que ir contra a norma-padrão é fazer um mau uso da língua e, portanto, ser contra lei, visto que foi a partir dos escritos literários que foram ditadas as leis de uso da língua.

A referida norma-padrão passa uma sensação de uma língua única, plena, pronta, parada no tempo. Segundo Fiorin (2002),

Pode-se entender daí que a gramática normativa decreta que é certo o que é errado, que o erro e os acertos em língua resultam do consenso dos gramáticos. Ora, nenhuma língua foi criada por um conselho de sábios, mas surgiu de usos ao longo de um processo histórico. Por isso, nenhum domínio linguístico, a não ser a ortografia, curva-se e decretos. (FIORIN, 2002, p. 30).

Na sequência, os autores reconhecem algumas das variedades linguísticas e também os diferentes tipos de contextos sociais nos quais há a interação verbal. Entretanto, ao fazer isso, eles pressupõem a existência de um uso da língua portuguesa visto como pior, ao mencionar que o material pretende fazer com que o aluno compreenda "o funcionamento e [faça] o melhor uso possível da língua portuguesa, em suas múltiplas variedades, regionais e sociais, e nas diferentes situações sociais de interação verbal". (CEREJA; MAGALHÃES, 2016, p. 3 grifos nossos).

Como um ponto positivo, podemos destacar a reflexão proposta a partir do poema de Patativa do Assaré, que abre o capítulo. Os autores sugerem a discussão das seguintes perguntas: "A língua portuguesa é uma só? Se não, de que dependem suas variações? O uso da língua pode gerar preconceito? Por quê?”. (CEREJA; MAGALHÃES, 2016, p. 77). Podemos constatar que esse tipo de exercício se enquadra nas práticas de letramento ideológicas, uma vez que, com o auxílio do professor, a discussão desse tópico pode levar os alunos a refletir sobre os "usos particulares da linguagem nos diferentes contextos socioculturais”. (BALADELI, 2014, p.229).

Entretanto, os exercícios propostos ao final da unidade para a fixação do conteúdo aprendido novamente reforçam a ideia preconceituosa e estereotipada de oposição entre o falante rural

\footnotetext{
9 "A norma-padrão não existe como uma língua de fato, pois ninguém fala português de acordo com ela em todos os momentos da vida." (CEREJA; MAGALHÃES, 2016, p. 77 grifo nosso). Há mais um problema nesta afirmação, pois, como coloca Bagno (2003), a norma padrão é um modelo abstrato, que não corresponde integralmente aos usos reais da língua. Logo, não há como "em algum momento da vida" falar o português cem por cento segundo esse modelo abstrato.
} 
e o falante urbano. O primeiro é colocado como caipira, não escolarizado e, portanto, pobre; e o segundo como urbano, escolarizado e, portanto, de uma classe social mais elevada.

Por fim, podemos destacar como outro ponto positivo do material o fato dele apresentar, em determinada parte do capítulo, a noção de adequação do registro linguístico, como demonstra o trecho a seguir:

O nível de formalidade pode variar independentemente de os textos produzidos serem orais ou escritos. Assim, pode haver textos orais extremamente formais, como uma conferência proferida em um grande evento, e textos escritos pouco formais, como um bilhete deixado na porta da geladeira de casa para alguém da família. (CEREJA; MAGALHÃES, 2016, p. 78).

Segundo Bortoni-Ricardo (2004, p.42), no que se refere ao processo de adequação do registro linguístico: "[é] preciso conscientizar o aluno quanto às diferenças para que ele possa começar a monitorar seu próprio estilo, mas esta conscientização tem de dar-se sem prejuízo do processo de ensino/aprendizagem, isto é, sem causar interrupções inoportunas". Pois, como menciona a autora, um trabalho inadequado com as variedades pode causar insegurança e até mesmo desinteresse por parte do aluno, causando, desse modo, o silenciamento de sua voz.

\section{Considerações finaIS}

O livro didático de língua portuguesa, muitas vezes, é uma ferramenta de grande importância no dia a dia do professor e dos alunos. Entretanto, essa valiosa ferramenta deve ser vista de maneira crítica, pois os discursos contidos nos textos e ilustrações podem ser fontes de poder e violência simbólica. O objetivo desse trabalho foi discutir as classes sociais e como elas são representadas no capítulo sete do livro didático Português: Linguagens. Ademais, buscamos fazer uma intersecção da representação das classes sociais apresentadas no livro com as variedades linguísticas atreladas a elas.

Constatamos que há no capítulo analisado algumas atividades que se enquadram no modelo de letramento ideológico, uma vez que, a depender do trabalho do professor, têm o potencial de fazer o aluno refletir sobre a sua língua e sua realidade, assim como refletir sobre a língua e realidade do outro. Todavia, o capítulo trabalha apenas com a dicotomia de classe social pobre/rico, desconsiderando as demais classes sociais que fazem parte do contínuo. Além disso, essa oposição é feita de maneira estereotipada, apresentando representações cristalizadas das classes mais baixas da pirâmide social.

No que concerne às variedades linguísticas representadas por essas classes sociais, embora haja alguns problemas conceituais, podemos destacar como aspecto positivo a valorização que os autores dão à noção de adequação do registro linguístico, uma vez que é a 
partir do reconhecimento linguístico que se criam as condições necessárias para uma efetiva discussão a respeito da língua portuguesa. Uma discussão sem juízo de valores, sem preconceito ou discriminação.

À vista disso, reafirmamos a relevância dos trabalhos que têm como objetivo a análise de livros didáticos, pois um ensino crítico só é possível a partir muitas reflexões. Discutir temas como identidade e representação de classe social é, antes de tudo, dar voz àqueles que sempre foram deixados à margem.

\section{REFERÊNCIAS}

ANDRADE, L. T. Do dialeto da classe educada brasileira, pode-se falar? In: AÇÃO EDUCATIVA. Por uma vida melhor: intelectuais, pesquisadores e educadores falam sobre o livro. São Paulo: Ação Educativa, 2011 p. 41-41. Disponível em: <https://social.stoa.usp.br/articles/0016/2718/ DossiA___Por_uma_vida_melhor.pdf $>$. Acesso em 19 de abr. 2018.

BAGNO, M. Preconceito lingüístico: o que é, como se faz. 20. ed. São Paulo: Loyola, 2003.

BALADELI, A. P. D. Questões de identidade em sala de aula: que sentidos de brasilidade apresentam os livros didáticos? In: FERREIRA, A. de J. (Org.). As Políticas do Livro Didático e Identidades Sociais de Raça, Gênero, Sexualidade e Classe em Livros Didáticos. Campinas, SP: Pontes Editores, 2014, p. 225 - 242.

BORTONI-RICARDO, S. M. Educação em língua materna: a sociolinguística na sala de aula. São Paulo: Parábola, 2004.

CEREJA, W. R.; MAGALHÃES, T. C. Português: Linguagens. São Paulo: Saraiva, 2016. CYRANKA, L. F. M. A pedagogia da variação linguística é possível? In: FARACO, C. A; ZILLES, A. M. S. (Orgs.). Pedagogia da variação linguística: língua, diversidade e ensino. São Paulo: Parábola, 2015, p. 31-51.

DAMBRÓS, L. P. Construção das identidades sociais de raça com intersecção de classes nos livros didáticos de inglês do ensino médio aprovados pelos PNLDs de 2012 e 2015. Ponta Grossa, 2016.

FARACO, C. A. Norma culta brasileira: Construção e ensino. In: FARACO, C. A; ZILLES, A. M. S. (Orgs.). Pedagogia da variação linguística: língua, diversidade e ensino. São Paulo: Parábola, 2015, p. 19-30.

FERREIRA, A. de J. Identidades sociais de raça, gênero, sexualidade e classe nos livros didáticos de língua estrangeira na perspectiva da linguística aplicada. In: FERREIRA, A. de J. (Org.). As Políticas do Livro Didático e Identidades Sociais de Raça, Gênero, Sexualidade e Classe em Livros Didáticos. Campinas, SP: Pontes Editores, 2014, p. 91 - 120. 
FIORIN, J. L. Os Aldrovandos Cantagalos e o preconceito linguístico. In: SILVA, F. L.; MOURA, H. M. M. (Orgs.). O direito à fala: a questão do preconceito linguístico. 2. ed. rev. Florianópolis: Insular, 2002, p. 23-37.

GNERRE, M. Linguagem, escrita e poder. São Paulo: Martins Fontes, 1985.

JORGE, M. L, S. Livro didático de línguas estrangeiras: Construindo identidades positivas. In: FERREIRA, A. de J. (Org.). As Políticas do Livro Didático e Identidades Sociais de Raça, Gênero, Sexualidade e Classe em Livros Didáticos. Campinas, SP: Pontes Editores, 2014, p. 73 - 88.

JOVINO, I. S. Representação de negros e negras num livro didático de espanhol: alguns apontamentos. In: FERREIRA, A. de J. (Org.). As Políticas do Livro Didático e Identidades Sociais de Raça, Gênero, Sexualidade e Classe em Livros Didáticos. Campinas, SP: Pontes Editores, 2014, p. 121 - 142.

MASTRELLA-DE-ANDRADE, M. R; RODRIGUES, J. A. A construção de identidades no livro didático de inglês: classe social, raça e outro. In: FERREIRA, A. de J. (Org.). As Políticas do Livro Didático e Identidades Sociais de Raça, Gênero, Sexualidade e Classe em Livros Didáticos. Campinas, SP: Pontes Editores, 2014, p. 143 - 162.

PENNYCOOK, A. Critical applied linguistics: a critical introduction. Mahwah, New Jersey and London: Lawrence Erlbaum Associates / Publishers LEA, 2001.

POSSENTI, S. Por que (não) ensinar gramática na escola. $6^{\text {a }}$ reimpressão. São Paulo: Mercado de Letras, 2000.

ROMERO, T. R. de S. Linguagem e memória no construir de futuros professores de inglês. Revista brasileira de linguística aplicada [online]. 2008, vol.8, n.2, pp. 401-420.

SENE, $R, A, R$ de. Identidade de raça, de gênero e sexualidade nas aulas de língua inglesa na visão das/os estudantes. Ponta Grossa, 2017.

STREET, B. Perspectivas Interculturais Sobre O Letramento. Tradução de BAGNO, M. Filologia e Linguística Portuguesa, n. 8, p. 465-488, 2006.

Recebido para publicação em 12 de Janeiro de 2020. Aceito para publicação em 6 de Março de 2020. 